\title{
IoT-based Building Automation and Energy Management
}

\section{Dr. Joseph A. Morgan, Texas A\&M University}

Joseph A. Morgan has over 20 years of military and industry experience in electronics and communications systems engineering. He joined the Engineering Technology and Industrial Distribution Department in 1989 and has served as the Program Director of the Electronics and Telecommunications Programs and as the Associate Department Head for Operations. He has served as Director of Engineering and Chief Technology Officer in the private sector and currently a partner in a small start-up venture. He received his BS degree in electrical engineering (1975) from California State University, Sacramento, and his MS (1980) and DE (1983) degrees in industrial engineering from Texas A\&M University. His education and research interests include project management, innovation and entrepreneurship, and embedded product/system development.

\section{Dr. Jay R. Porter, Texas A\&M University}

Jay R. Porter joined the Department of Engineering Technology and Industrial Distribution at Texas A\&M University in 1998 and is currently the Associate Department Head for Undergraduate Studies. He received the BS degree in electrical engineering (1987), the MS degree in physics (1989), and the Ph.D. in electrical engineering (1993) from Texas A\&M University. His areas of interest in research and education include product development, analog/RF electronics, engineering education, and entrepreneurship.

\section{Dr. Michael Johnson, Texas A\&M University}

Dr. Michael D. Johnson is an associate professor in the Department of Engineering Technology and Industrial Distribution at Texas A\&M University. Prior to joining the faculty at Texas A\&M, he was a senior product development engineer at the 3M Corporate Research Laboratory in St. Paul, Minnesota. He received his B.S. in mechanical engineering from Michigan State University and his S.M. and Ph.D. from the Massachusetts Institute of Technology. Dr. Johnson's research focuses on design tools; specifically, the cost modeling and analysis of product development and manufacturing systems; computer-aided design methodology; and engineering education. 


\title{
IoT-Based Building Automation and Energy Management
}

\begin{abstract}
As part of a NSF-funded ITEST grant, the ETID Department at Texas A\&M University is developing a STEM Teacher Education initiative that helps secondary education math and science teachers to better understand advanced technology concepts. This new initiative will be presented to a different groups of approximately twelve teachers each year for three consecutive summers to create a cadre of educators who are able to excite high school students and motivate them to choose engineering/technology career paths as they enter their undergraduate degree programs. This paper presents an overview of and results from the two-week workshop hosted during summer 2017. Included in this overview will be an outline of the building automation/energy management experiential learning that was undertaken and how IoT was integrated into this important technology discipline. Examples of edge devices, sensors, wireless communications, and IoT processes such as publishing, subscribing, and building sensor/actuator dashboards for IoT-based building monitoring and control systems will be provided. Evaluation data, teacher feedback and anecdotal information will also be presented. In addition to plans for upcoming summer activities, the paper will summarize the industrial support received for this initiative and how undergraduate students assisted in the development and presentation of a portion of the technical content and laboratory exercises.
\end{abstract}

\section{Introduction}

There is a national desire in the United States to promote interest among students in science, technology, engineering, and math (STEM). The idea being that this increased interest will translate into STEM college majors and subsequently produce the STEM professionals that the US needs. Promoting this interest is difficult in general, but this is particularly true with respect to the areas of engineering and technology. Many teachers may have an understanding of math and science, but few have extensive experience in engineering or technology. Promoting interest in engineering and technology requires a two-pronged approach: providing the necessary background for the teachers and developing interesting and compelling content for them to deliver to their students.

As part of a project funded by the National Science Foundation, a two-week summer professional development workshop introduced a group of 12 junior high and high school teachers to various aspects of engineering and technology. The workshop was focused on the development of activities around building automation using two exciting technologies: connected devices (often referred to as the Internet of Things - IoT) and additive manufacturing (known as 3D printing). The workshop provided the first of the two "prongs" of the approach; it provided background for the teachers about various aspects of the engineering design process and the two technologies that would be used in the developed activities. To provide background for the 3D printing, teachers were introduced to computer-aided design (CAD) and taught how to create basic CAD models using Autodesk Fusion 360. The introduction to IoT entailed teaching them about various aspects of how connected devices work, the hardware, communications protocols, and programming.

The second prong of the approach entailed creating compelling and interesting activities for the students. The first part of this was to use two widely talked about and emerging technologies (IoT and 3D printing). The second part was to create activities that were authentic and provided an opportunity for experiential learning. Experiential learning attempts to rectify 
what Kolb characterized as the "rejection" of the "real-world" by the educational establishment ${ }^{1}$. Namely, experiential learning allows students to experience, reflect, think, and act as part of a holistic educational experience ${ }^{2}$. Because the experiential learning model is based on a frame of the successive cycles between concrete and abstract concepts, a transfer from a theoretical lecture to the experiential activity or vice versa is claimed to be the sequential cycle for learning 1,3 . The students will be given the opportunity to use connected devices to collect data and learn about their school "environment". This can be coupled with math and science activities (e.g., graphing, hypothesis testing) to improve student understanding and interest. Authentic activities are those which address some actual need or purpose outside of educational activities ${ }^{4}$. The use of building automation as a platform for using these exciting new technologies contributes to the authenticity of the exercises. The focus of this work is on the technical aspects of the IoT instruction provided to the teachers.

For several years now, both policy makers and industry across the United States have recognized the need for an increased emphasis on science, technology, engineering, and mathematics (STEM) in the public education system. One of the main reasons for this is to help young minds develop an interest and desire to learn math and science early in their education. In this way, they are better positioned to consider and pursue STEM related careers after high school. To this end, agencies such as the National Science Foundation and others have developed funding programs focused on the development of methodologies and curricula that can support the introduction of STEM in the current K-12 educational system. As a result, public educational systems and institutions of higher learning are responding. As an example, the State of Texas has developed a set of STEM academies (T-STEM) devoted to introducing STEM as part of the secondary curriculum and increase students' college readiness for entering college-level STEM programs of study. As of 2013, 65 separate T-STEM Academies have been created and are operating. However, common problem that many of these programs encounter is how to introduce STEM into existing junior-high and high school curricula. This is a problem that several faculty members in the Department of Engineering Technology and Industrial Distribution (ETID) at Texas A\&M are interested in solving.

The ETID Department is one of fourteen departments in the College of Engineering. ETID is unique in that it is primarily an undergraduate department supporting four separate academic programs and over 1700 undergraduate students. As such the faculty have a strong focus on undergraduate teaching in addition to the requirements of performing scholarly research, disseminating knowledge, and engaging in service activities. Not surprisingly, it is this focus that drives many faculty to develop education-centered research projects and engage in education-related service including STEM outreach to K-12 teachers and students. Examples of these activities include:

- Beginning approximately eight years ago, faculty in the Electronic Systems Engineering Technology program developed a mobile robotic kit that could be used with junior-high and high school students to teach them about robotics, embedded hardware/software, and autonomous control. This kit has since been used by faculty to deliver multiple STEM summer camps on the Texas A\&M campus, short courses at regional junior-high and high schools and teacher workshops.

- Faculty in Industrial Distribution and Manufacturing and Mechanical Engineering Technology are part an NSF-funded multidisciplinary project to introduce a selfsustaining manufacturing and distribution program to students living in communities in South Texas. 
- Faculty in Electronic Systems Engineering Technology have collaborated with NASA to develop and support and embedded monitoring and control system that allows high school students to easily develop space-based experiments that can be delivered to and run on the International Space Station.

- A faculty member in Industrial Distribution brought the First Lego League to the region and runs the annual competition which involves hundreds of K-12 students in STEM activities and competitions.

- Faculty in Industrial Distribution and Manufacturing and Mechanical Engineering Technology received a National Science Foundation (NSF) Advanced Technological Education (ATE) grant for their collaborative research in providing an adaptive learning environment for high school and community college students who are interested in acquiring high value manufacturing skills.

Most currently, multiple faculty across several of the programs have leveraged their past efforts, industry connections, technical research, and experience in STEM to create a proposal to the NSF's ITEST program. The goal of the proposal is to pursue research that leverages industry members, K-12 teachers, and actual engineering focus areas that are of general interest to young minds to create educational experiences for junior-high and high school students that excite their interest in STEM concepts and motivates them to pursue higher education and/or careers in STEM related fields.

\section{ITEST}

$\underline{\text { Overview }}$

Because of the multidisciplinary composition of ETID, active faculty research in the areas of Internet of Things (IoT)/ building automation/additive manufacturing, and faculty expertise in STEM educational research, multiple members of the faculty submitted a proposal to the NSF ITEST program titled "Connected STEM - Promoting STEM Education through Connected Devices and Building Automation." The concept of the proposal is to use building automation and energy efficiency as a platform to develop fourth through twelfth grade students' interest in pursuing post-secondary schooling and/or occupations in STEM related disciplines. Building automation and energy efficiency were chosen as the focus areas due to their popularity and ubiquity. Students are well aware of building automation since these concepts are used in their homes, schools and other buildings they frequent. In addition, energy efficiency is a topic of general interest to youth, especially due to the current conversations about climate change and renewable energy resources. To ensure a technical component to the concepts being proposed, the focus areas will be supported with education in the internet of things, controls/automation, and additive manufacturing. These areas were chosen due to their currency, availability of rewarding STEM careers, and ability to develop interest and excite students. As of fall 2016, the project was funded through the ITEST program.

The project is broken into three parts: finding 4th through 12th grade teachers for involvement in the project and educating them in the technical areas discussed above, supporting ongoing curriculum development and delivery in regional schools through training and technical assistance, and assessment of the effectiveness of the ITEST project to ensure that goals are being met.

\section{$\underline{\text { Objectives }}$}


This project is designed to promote interest in STEM through promoting junior high and high school student interest, skills, knowledge, and career aspirations in engineering through authentic engineering design activities related to building automation. The goal will be accomplished through five objectives.

- Objective 1: Increase teacher use of engineering design and product development process.

- Objective 2: Increase student understanding of the engineering design process and engineering careers.

- Objective 3: Stimulate student interest in math and science.

- Objective 4: Increase high school student career interest and opportunities in building automation.

- Objective 5: Promote parental understanding of engineering careers and technological development.

\section{IoT Technology}

The Internet of Things is the network of devices, sometimes referred to as objects, or things, that incorporate embedded intelligence, sensors, actuators and network connectivity. Each of these network devices is capable of collecting and sharing data and information and/or causing control changes within its own devices or other devices connected to the network. According to www.internetsociety.org, there could be as many as 100 billion connected IoT devices by the year 2025 with a global economic value of more than $\$ 11$ trillion by the year 2025. Clearly, this technology will have a significant impact on a wide range of industries and our daily lives for years to come and will offer STEM-based careers ranging from design engineer to system installation and maintenance. In addition to the economic aspects of the technology, IoT also offers interesting and motivating challenges for secondary education. Disseminating an understanding and appreciation for IoT at the elementary, junior high and high school levels will require equipping science, math and engineering teachers with the fundamentals of IoT and an appreciation of how this game-changing technology can be integrated into secondary education.

The IoT will and is being developed through the interconnection of intelligent objects over the internet. Most of these objects will have sensing capability and will provide data through the monitoring of one or more physical properties of the target system. An example of this would be the ability to monitor the temperature, light and motion in each room of a house and upload these data to the Internet. Although monitoring systems have used the internet transport data to a remote location, both sides of the monitoring system need to be connected and generally there was a human in the loop to make decisions. IoT technology takes this structure to the next level and has the ability to remove the human from the control process and also support system architectures that can continue to operate if the remote end of the system was not on line. These two major operational factors are what differential IoT from other remotely connected systems.

To accomplish these objectives, the IoT system is generally composed of multiple objects or devices (things). Both wired and wireless communications are used to connect an object to the internet. Once an object has Internet connectivity, it can "publish" its data to a "broker". The "broker" will accept these data and provide for short to long-term storage. When another object with the proper credentials, joins the group, it can "subscribe" to one of more of the data elements that has been published to the "broker". In addition, decisions or actions that have been 
determined by an intelligent device can also be "published" to the "broker". When another object/device "subscribes" to this control information, it can carry out a new command or make a performance change through the adjustment of one or more actuators connected to it. An example of this would be to add a decision making thing to the above example that "subscribes" to the temperature, light and motion data that has been "published" by the sensing devices. Using a control algorithm, the decision making device would "publish" new actuator positions to the broker that would store these instructions. When a third actuator device logs into the IoT system, it can subscribe to the subset of instructions pertaining to it actuators and make adjustments based on the instructions published by the decision-making device(s). This system can operate without constant human intervention and does not have to be fully connected at all times - thus the creation of an IoT system. Finally, other authorized and properly identified objects can gain access to the broker to subscribe to sensor data, decision algorithm outputs, or actuator status for real time monitoring and display. Some or all of this information can be made available anywhere in the world at any time, day or night. Thus providing an IoT-based system that can better management the environment of a home or building while conserving energy and improving human comfort and safety is possible through the use of IoT technology.

Because building monitoring and energy management is understood or at least appreciated at some level by all $\mathrm{K}-12$ students, this application was chosen to present IoT technology. Another reason that building monitoring and energy management was selected was because of the direct and clear relationship to math and science. Finally, this choice of IoT application included all IoT components (Edge device, Broker, Decision Making) with the associated publishing and subscribing functions being clearly represented.

To equip the science and math teachers with a basic capability that was easy and straightforward to understand and teach, an IoT Development system was required. The kit had to have the ability to represent the building monitoring and energy management functions while easily being replicated at a reasonable cost. Whenever possible free/evaluation resources were selected and the NSF faculty team sought donations from the private sector to reduce costs. It was also desirable for the development kit to support the additive manufacturing technology and engineering design process also being taught as part of the summer teacher workshop.

The selection of the intelligent embedded device was critical to the development of the IoT Kit. A number of options were evaluated prior to the faculty team choosing the Texas Instrument CC 3200 LaunchPad and the BoostXL SensorPack module. This selection provided a number of important capabilities including:

- Small form factor

- Power efficient

- Multiple environmental sensors

- On-board wireless (802.11) access point

- Add-on modules

- PWM capable digital outputs

- 5VDC or 3.3VDC single source power

- Energia (Arduino-like) software development environment

- USB programming interface to computer

- Extensive user community with numerous example projects

Once the embedded target was selected and configured, additional sensors, actuators and signal conditioning circuitry was selected for the kit. With the addition of the BoostXL- 
SensorPack multiple environmental sensor technology was added to the CC3200 LaunchPad. The sensor pack provides:

- OPT3001 Ambient Light Sensor

- TMP007 Contactless (IR) Temperature Sensor

- BMM150 3-axis Geomagnetic Sensor

- BMI160 6-axis Inertial Measurement (accelerometer and gyro)

- BME280 Integrated Environmental Unit (pressure, temperature, humidity)

Using these building blocks, the NSF faculty team created a development kit for the teachers to use to develop code, test wireless connectivity, build dashboards and simulate most functions and capabilities needed for a building monitoring / energy management IoT system. As shown in Figure 1, the final IoT Teacher Development Kit included the following items. Battery pack

- Motion Sensor

- Relay

- AC Outlet

- LaunchPad/BoostXL SensorPack

- 3D Printed Enclosure

- H-Bridge Driver

- DC Motor

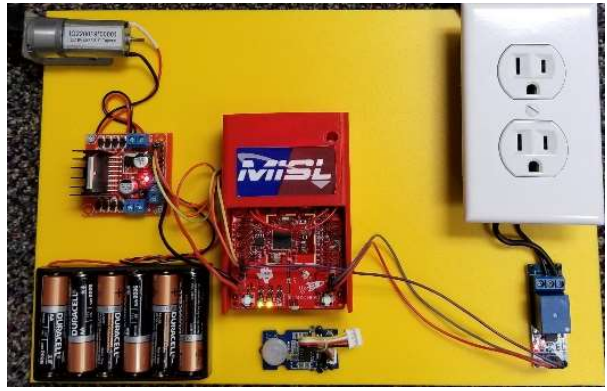

Figure 1. IoT Development Kit.

In addition to creating the IoT Development Kit hardware, a Broker capability is needed to support the publishing, data storage, and subscribing processes necessary to implement the IoT system. After review and evaluation of a number of on line environments, the NSF faculty chose the Cayenne mydevices.com drag and drop IoT project builder to provide both the broker function and a dashboard to visualize data, set up rules, schedule events and more. An example of the dashboard created to support the IoT Development Kit is shown in Figure 2. Cayenne provides free access to its resources for educational purposes and has excellent user support. The dashboard is available for PCs and Macs as well as App support for Android and iPhone.

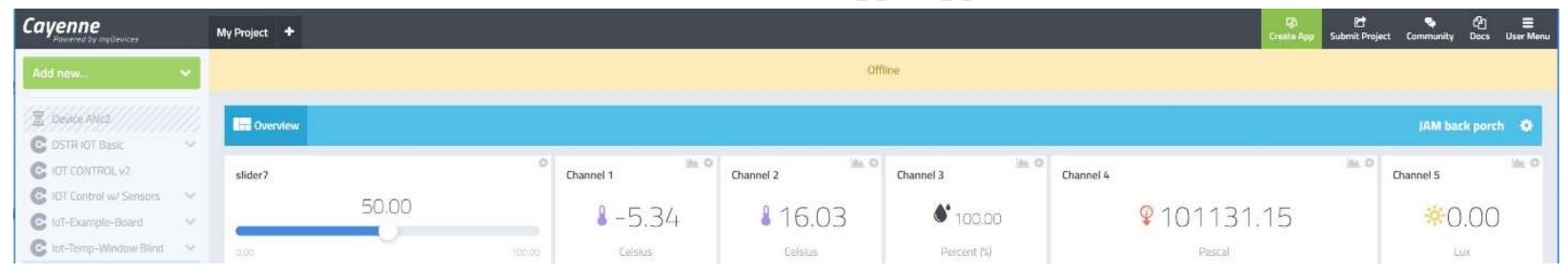

Figure 2. Cayenne Dashboard Example.

Using Energia, the LaunchPad can be configured to log into a wireless (802.11) network that provides Internet access. Once connected to the Internet, the LaunchPad's Energia code then logs into a Cayenne Thing that has been previously set up using the dashboard. The LanuchPad then publishes data obtained from its suite of sensors and/or controls analog and digital actuators properly interfaced to the LaunchPad.

This low-cost system can be configured and operated as a complete building monitoring and resource management simulator. Data such as light intensity or motion can be obtained from 
the IoT edge device and published to the Cayenne dashboard. These data can be processed graphically to produce control values which the LaunchPad can subscribed to. Any changes in these values can institute a change in output generated by the LaunchPad. The motion or change in light intensity might cause a change in the relay control value such that the LaunchPad would then change a digital output pin from a low state to a high state. The relay would close providing 110 VAC to the outlet plug on the IoT Development Kit, thus turning on a lamp.

Likewise, the temperature and humidity sensor reading could be used in a separate algorithm to determine the speed of a fan. The algorithm could change the duty cycle value for the fan which the LaunchPad is subscribed to causing a change to its PWM digital output which is then power amplified by the H-Bridge Motor Driver circuitry thus varying the speed of the fan attached to the DC motor on the IoT Development Kit.

The curriculum that accompanied the IoT portion of the workshop stressed the use of software in creating a complete IoT system. At the conclusion of each module, the teachers were instructed to implement some aspect of the system. The lab projects included:

- Project 0 - Blink (System setup checkout)

- Project 1 - Data to the screen

- Project 2 - Data to a file

- Project 3 - Wireless data

- Project 4 - Data to the cloud

Add sensor(s)

Cloud graphics

- Project 5 - Control element

Add capability

- Project 6 - Messaging

The first four projects allowed the teachers to construct their IoT Development Kit and check out each of the subsystems. In addition, they were able to fully download, install, and configure their Energia development environment while becoming familiar with the software, hardware and data formats provided by the TI LaunchPad/BoostXL-SensorPack. The remaining lab projects allowed the teachers to use the LaunchPad as an edge device. In doing so, they were able to generate the Energia code that published sensor data to the Cayenne Broker while subscribing to other control information posted to the dashboard. The teachers were also able to access the data in tabular and graphical form. Finally, they were able to create and send text messages based on user-defined limits for each environmental sensor. With these seven projects, the teachers realized the requisite knowledge necessary to configure and deploy a fully functioning IoT-based building monitoring and energy management system of their own. In addition, each teacher was able to create a teaching module that include IoT concepts and deliver this module to a representative student during the workshop.

\section{Results/Assessment}

Summer Workshop

The first summer workshop for the teacher participants was conducted at the end of July 2017. The workshop lasted two weeks and the teachers traveled from several areas including Houston, Dallas and San Antonio to Texas A\&M and resided in one of the dorms on campus. Twelve participants were chosen specifically to include a broad range of demographics including gender, age, ethnicity, and grade levels (see Table 1). This was done intentionally to for 
research purposes and so that continuous improvement data could be collected for subsequent workshops.

Table 1 - Summary of Participant Demographics

\begin{tabular}{|l|l|l|l|l|l|}
\hline \multicolumn{2}{|c|}{ Gender } & \multicolumn{2}{c|}{ Ethnicity } & \multicolumn{2}{c|}{ Grade Level } \\
\hline Female & $\mathbf{5 8 \%}$ & Hispanic & $\mathbf{2 5 \%}$ & $\mathbf{6}^{\text {th }}$ & $\mathbf{1 7 \%}$ \\
\hline Male & $\mathbf{4 2 \%}$ & Black & $\mathbf{2 5 \%}$ & $\mathbf{7}^{\text {th }}$ & $\mathbf{0}$ \\
\hline \multicolumn{2}{|c|}{ Age } & Asian & $\mathbf{8 \%}$ & $\mathbf{8}^{\text {th }}$ & $\mathbf{1 7 \%}$ \\
\hline Min & $\mathbf{2 4}$ & White & $\mathbf{5 0 \%}$ & $\mathbf{9}^{\text {th }}$ & $\mathbf{5 8 \%}$ \\
\hline Max & $\mathbf{5 7}$ & & & $\mathbf{1 0}^{\text {th }}$ & $\mathbf{5 8 \%}$ \\
\hline Mean & $\mathbf{3 9}$ & & & $\mathbf{1 1}^{\text {th }}$ & $\mathbf{7 5 \%}$ \\
\hline & & & & $\mathbf{1 2 t h}^{\text {th }}$ & $\mathbf{5 8 \%}$ \\
\hline
\end{tabular}

The workshop was divided into two contiguous one week sessions, the first devoted to education and the second devoted to implementation. During the first week, the teachers attended lectures and interactive sessions on engineering design, building automation, energy, internet of things (IoT), and additive manufacturing. Through these sessions, they were introduced to and given a set of tools that could be used in the classroom including a 3D printer, a power meter, and a suite of IoT embedded systems with appropriate sensor technology. Guest speakers were also invited to speak with the teachers about relevant technologies and the career paths for their students. During the second week, the participants were then asked to implement potential lesson plans that integrated the concepts presented in the first week with their standard lectures and curricula. They were then given two days to try out their lesson plans with real students and develop improvements. Over the course of the workshop, the teachers were given several surveys as well as a pre- and post- survey to gauge their level of learning, interest in the material, ability to adopt the material in their existing classrooms, and satisfaction with the workshop.

\section{$\underline{\text { Survey Results }}$}

As stated previously, the goal of the workshop was to introduce the participants to general engineering concepts such as design and product development as well as to specific technologies that including building automation, energy efficiency, internet of things, and additive manufacturing. Pre- and post- surveys were used to determine the effectiveness of the workshop, of increasing participant knowledge, and determining the ability of the participants to implement the concepts in their classrooms. A summary of the pre and post workshop surveys is contained in Table 2.

Table 2 - Summary of Pre/Post Workshop Survey Results

\begin{tabular}{|l|l|}
\hline \multicolumn{1}{|c|}{ Category } & \multicolumn{1}{|c|}{ Pre to Post Workshop Survey Change } \\
\hline Describe Engineer & Very general to more specific responses \\
\hline Understanding of Engineering & \\
\hline Impact on improving life & $4 \%$ increase \\
\hline Different from science & $12 \%$ increase \\
\hline Career value & $2 \%$ increase \\
\hline "Art" aspect & $16 \%$ increase \\
\hline Diverse group of people & No change $(4.2 / 5)$ \\
\hline
\end{tabular}




\begin{tabular}{|c|l|}
\hline Confidence in Workshop Concepts & \\
\hline $\begin{array}{c}\text { Building automation and } \\
\text { energy management }\end{array}$ & $40 \%$ increase \\
\hline Internet of Things technology & $48 \%$ increase \\
\hline Engineering design process & $28 \%$ increase \\
\hline Engineering design challenges & $24 \%$ increase \\
\hline Teacher Satisfaction & \\
\hline Account for background and abilities & $4.2 / 5$ \\
\hline Use of time & $4.5 / 5$ \\
\hline Resource awareness & $4.7 / 5$ \\
\hline Incorporate into teacher's classroom & $4.5 / 5$ \\
\hline Recommend workshop to their peers & $100 \%$ of participants would recommend \\
\hline
\end{tabular}

Results of the surveys include:

- When asked to describe what an engineer does and how products are designed, the participants gave very general answers in the pre-survey. At the end of the workshop, they were much better able to give specifics about the role and career of an engineer. This meets one of the important goals of the workshop, to help teachers better communicate the role of an engineer to their students.

- Teachers were asked to quantify their understanding of different aspects of engineering on a scale of 1 to 5. Through a comparison of pre- and post- survey data, the participants demonstrated an increased level of understanding of the impact of engineering on improving life ( $+4 \%$ increase), the difference between science and engineering $(+12 \%$ increase), the value of an engineering career ( $+2 \%$ increase), and the "art" aspect of engineering $(+16 \%)$. When asked if engineers were a diverse set of people, there was no change between pre- and post- $(4.4 / 5)$.

- Over the course of the workshop, teachers demonstrated an increase in confidence (based on survey results similar to the previous bullet) related to using the concepts taught such as: building automation and energy efficiency $(+40 \%)$, the internet of things $(+48 \%)$, using the engineering design process $(+28 \%)$, and using engineering design challenges with their students $(+24 \%)$.

- Overall, teacher satisfaction with the program was very high. Teachers rated the program well in terms of taking into account their backgrounds and abilities (4.2/5), making good use of their time (4.5/5), making them aware of the resources available to them (4.7/5), and providing them with the support necessary to incorporate subject taught into their classroom $(4.5 / 5) .100 \%$ of the teachers said they would recommend the workshop to their peers.

\section{Lessons Learned to Date}

Based on the workshops and the follow-ups to date, there are several lessons learned that are being considered for future workshops and participant cohorts. These include:

- Continuous Engagement - While the enthusiasm of the participants is high during the workshop, they get distracted by the day-to-day duties after returning to their schools. It is important to ensure continuous engagement with the teachers throughout the school year. This is being accomplished by assigning a faculty mentor to each participant (two participants per faculty member) to ensure that contact is being made with them and that 
support is being offered. In addition, each faculty member is making a minimum of two trips to visit with each of their mentees during the school year for face-to-face quality time.

- Standardized Experimental Environment - The original expectation was that each participant would develop custom curriculum to suit their classroom based on the learning objectives of the summer workshop. Because this seemed daunting to some of the participants, a standardized building automation environment for use in the classroom is being developed. Three separate sets of undergraduate capstone students in ETID are being tasked with the development of a miniature "building" where IoT, additive manufacturing, and building automation/energy efficiency concepts can be applied. Constraints given to the capstone teams for this emulation environment include that it be small, low-cost, and real-world

- Emphasis on Math and Science Teachers - In the initial cohort of participants, some of the teachers selected were from engineering academies while the rest taught more traditional science and math courses. As expected, the teachers that were already involved in engineering education were very enthusiastic about the goals of the workshop. However, the workshop also demonstrated that the math and science teachers were not only interested in concepts being taught in the workshop, they were also very excited about incorporating those concepts into their classrooms as a methodology to apply math and science to the real-world. Feedback from those teachers indicated that the use of real-world projects in their classrooms have repeatedly demonstrated that by providing an application-oriented context for the subject matter being taught stimulates an interest in the subject. This is directly in-line with the project's third objective. In the long run, it is those teachers that can have the largest impact on promoting STEM as a career path to young students. Thus, it is anticipated that future workshops with place an emphasis on traditional math and science teachers in the selection process.

- Online Sharing of Ideas - During the workshop, the teachers pushed heavily for a way to share their ideas and curricula between each other during the school year. Thus a wiki was created that was accessible by all of the participants. This wiki has also proven useful as a way to monitor the participants and their progress.

\section{Future Work}

Based on the highly successful STEM teacher workshop conducted during the summer 2017, and the teachers' desires to have more baseline examples, the ESET faculty sponsored a Fall 2017/Spring 2018 Capstone Design project to create a reference design for a low-cost, easy to build "house" that could be monitored and environmentally controlled. As shown in Figure 3, the project included the layout and implementation of a three-room house that has a removable roof and windows. Within each room of the house, a LaunchPad/BoostXL-SensorPack monitors a number of environmental variables such as temperature, humidity, light intensity, etc. These data are then published to the Cayenne broker for storage and display. The Launchpad, attached to a "mother board" designed by the Capstone team, controls multiple environmental actuators including heating, air conditioning (pump, blower and dampers), lights, fans, and a window blind. 


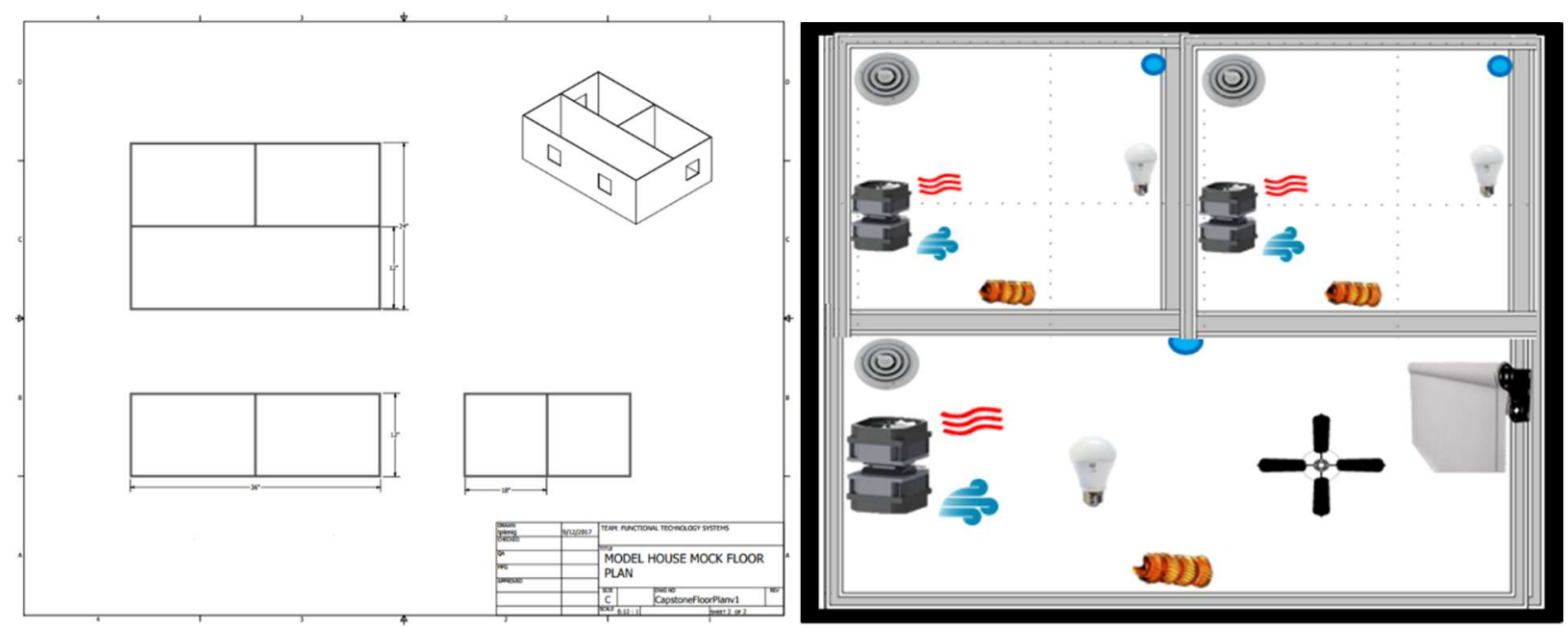

Figure 3. Three-room Model.

By having a removable roof, the STEM students can investigate the insulation properties of various materials, placement of sensors and actuators, and the effects of using a window blind to assist in the control of light and heat. By moving all these data to the Internet cloud, the students will be able generate text-based recordings over time which can then be graphed using Cayenne toolbox or downloaded and reduced/analyzed using Excel or other spreadsheet software.

With the experienced gained from the Summer 2017 STEM Teachers Workshop and the added capability provided by two Capstone teams, the ITEST faculty plan to enhance the 2018 workshop to make it even a better experiential learning opportunity. The overall goal being considered at this time is to have teams of three to four teachers working together to design, build, instrument, and program an IoT House that can be monitored and controlled without human intervention. The project-based approach should improve the teachers overall knowledge and capabilities in all the major areas of the ITEST grant while providing additional motivation to learn the technical/engineering areas of building automation/energy management, IoT, and additive manufacturing from a system of systems and product design perspective.

\section{Conclusions}

The results of the first workshop were very positive and a number of areas for improvement had been identified. From an engineering technology faculty perspective, each of the four technology area teams has generated a list of additional topics and experiential learning opportunities that will be integrated into the summer 2018 workshop. Together with these new topics and experiences, multiple capstone projects have been initiated to add more real-world aspects and interest in the laboratory work which the teachers will accomplish during the twoweek workshop. In addition, better assessment processes have been implemented to select the second group of twelve teachers so that a more diverse cross section can be brought together to develop and share new educational modules that integrate a wider spectrum of math and science concepts. In so doing, more examples of these four engineering technologies can be used in motivating secondary education students to select STEM career paths at the college level. 


\section{Acknowledgement}

This material is supported by the National Science Foundation under DRL Grant Numbers 1615019 and 1614496. Any opinions, findings, conclusions, or recommendations presented are those of the authors and do not necessarily reflect the views of the National Science Foundation.

\section{References}

[1] Kolb, D.A., (1984). Experiential learning: Experience as the source of learning and development: Prentice-Hall.

[2] Kolb, D.A., Boyatzis, R.E. \& Mainemelis, C., (2001). Perspectives on cognitive, learning, and thinking styles. In Sternberg, R.J. \& Zhang, L.F. eds. Perspectives on thinking, learning, and cognitive styles. L. Erlbaum Associates.

[3] Sălăvăstru, D., (2014). Experiential learning and the pedagogy of interrogation in the education of adults. Procedia - Social and Behavioral Sciences, 142 (0), 548-552.

[4] Strobel, J., Wang, J., Weber, N.R. \& Dyehouse, M., (2013). The role of authenticity in design-based learning environments: The case of engineering education. Computers \& Education, 64 (0), 143-152. 